\title{
LOS MEMORIALISTAS O DE LOS HÉROES CONTEMPORÁNEOS
}

\author{
THE MEMOIRISTS OR ABOUT CONTEMPORARY HEROES
}

\author{
Gaetano Antonio Vigna \\ Universidad de Valladolid \\ g.vigna88@gmail.com
}

Recibido: 11.12 .2019

Aceptado: 04.05.2020

\begin{abstract}
RESUMEN: En esta contribución, a partir del análisis de los libros de memorias de Juan Luis Panero y Josefina Aldecoa, se reflexiona sobre las técnicas compositivas empleadas por los dos escritores, testigos directos de la Guerra Civil y/o de la subsiguiente represión franquista, a la hora de ofrecer su autorretrato. El análisis evidenciará la presencia en estos textos de una estructura similar a la que rige el relato del héroe. Y, más concretamente, se examina el vínculo existente entre los recuerdos de la vida personal de cada memorialista y las unidades temáticas en las que se articula la aventura del héroe, desde la llamada a la aventura, pasando por la etapa de las pruebas que han de mostrar su heroísmo, hasta el regreso a su comunidad de pertenencia. De esta manera, será posible ver no solo la manera en la que se eleva la vida personal a la categoría de mito, sino también la razón por la que dichas estructuras heroicas se revitalizan en la escritura memorialística contemporánea.
\end{abstract}

Palabras Clave: Juan Luis Panero, Josefina Aldecoa, memorias, mito, héroe

ABSTRACT: This paper analyses the memoirs of two Spanish authors, Juan Luis Panero and Josefina Aldecoa, witnesses of the Spanish Civil War and/or of the following Francoist repression, focusing on the technique they make use of in order to create their self-portrait. The study of these literary works will show the use of the same pattern that are a characteristic of the hero's journey. More specifically, we study the affinity between memoirists' personal recall of the past and the stages through which a myth is usually organized, starting with the initial call to go on adventure, the road of trials he must get over and, finally, the hero's return to his ordinary world with the treasure he gained. In this way, it will be possible to understand fully not only how an ordinary life is converted 
into myth, but also the reason why these mythemes revitalise themselves in the contemporary memoirs.

Keywords: Juan Luis Panero, Josefina Aldecoa, Memoirs, Myth, Hero

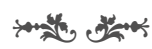

\section{INTRODUCCIÓN}

Desde finales de los años setenta del siglo xx se observa, en el panorama editorial español, una inflación de la narrativa memorialística relacionada con el tema de la guerra civil y la represión franquista (Becerra Mayor 2015). La tendencia ahonda sus raíces en el proceso de amnesia que agudizó la represión hacia los vencidos en el periodo de transición a la democracia. Considerando la proliferación de memorias en torno a dicho momento temporal, a lo largo de esta contribución analizaremos el influjo de la Historia sobre la personalidad en desarrollo de dos escritores, Juan Luis Panero y Josefina Aldecoa, tal y como estos lo cuentan en sus memorias. De esta manera, responderemos algunas preguntas que estimamos fundamentales: ¿qué tipo de personaje se construye en el acto memorístico?; ¿qué resulta de un sujeto nacido del diálogo entre el recuerdo del pasado y las aspiraciones estéticas del presente? y, por último, ¿qué sentido tiene este tipo de producción literaria en el marco del siglo XXI?

Para situar el tema es importante precisar que en las memorias el yo autoral cumple un metafórico viaje de vuelta al pasado, dejando constancia en el texto de su mirada sobre los eventos más significativos de su vida privada y el entorno social. En esta variante de espacio autobiográfico que son las memorias, todos los elementos de la vida personal del evocador se desprivatizan y se incorporan a la memoria colectiva (Fernández Prieto 1997: 69). Así, a partir del vínculo entre lo privado y lo social, el autor-narrador-personaje nos muestra el camino emprendido para llegar al presente de la escritura. Una escritura, claro está, que, exhibiendo un "doble estatuto, el referencial [...] y el performativo" (Pozuelo Yvancos 2004: 177), es pasible de ficción. Y es que, entre el carácter errático de la memoria y la conversión de la vida personal en objeto de performance literaria, la trayectoria vivencial del memorialista se enriquece con los detalles de sus actancias que, a nuestro ver, nada desmerecen de las hazañas heroicas. En efecto, ¿cuán heroísmo trasuda de las vidas de todos los que vivieron la dictadura y lucharon contra su limitante orden impuesto?

Como será posible apreciar en las obras analizadas, la ordenación de la vida personal sigue unos topoi del discurso autorrepresentacional que, siguiendo a Sylvia Molloy (1984), hemos nombrado autobiografemas. A estas unidades mínimas del género hay que imaginarlas como contenedores temáticos donde el escritor inserta, ordena y elabora sus propias vivencias. Y en efecto, lo que 
se manifiesta de manera premeditada a través de la escritura es el recuerdo de todas aquellas escenas de la infancia, de la adolescencia o de la edad adulta que, escogidas en el presente escritural y elevadas a la categoría de mito, definen una personalidad dada. Si sometemos dichos autobiografemas a un estudio más detallado, veremos cómo estos se pueden encasillar en tres grandes etapas del escenario mítico que el estudioso Joseph Campbell (1959) señala en su obra El héroe de las mil caras. Es decir, la separación o partida, las pruebas y la victoria de iniciación y, finalmente, el regreso y la reintegración a la sociedad (Campbell 1959: 40-41).

En palabras del mitólogo estadounidense, "el héroe [...] es el hombre o la mujer que ha sido capaz de combatir y triunfar sobre sus limitaciones históricas, personales y locales y ha alcanzado las formas humanas generales, válidas y normales" (Campbell 1959: 26). También nuestros evocadores, burgueses o pequeños burgueses, han superado los límites impuestos por la familia y la sociedad, sirviéndose de la escritura para distinguirse de los demás miembros de su comunidad y así alcanzar los méritos que les corresponden. Su lucha, rememorada desde un presente de libertades democráticas, brota del rechazo del asfixiante clima dictatorial que los rodea, culminando en lo que Fernando Savater (1986) define el sueño heroico por excelencia: la autonomía y la independencia. Asegura el conocido filósofo español que "la democracia es la realización ético-política más inequívocamente heroica que se han propuesto los hombres" (Savater 1986: 125). A partir de esa indomable aspiración, nuestros memorialistas dan a conocer el recuerdo de sus actancias en un tiempo carente de libertad, cristalizando en sus textos un exceso de cualidades morales que los convierten en ejemplos a imitar, "modelos de todo aquello que normativamente ha de pensar y ha de hacer el ser humano" (Duch 1998: 58).

Sus libros de memorias parecen integrar elementos temáticos propios del relato mítico, desde la llamada a la aventura -y con ella toda una serie de ocurrencias que, en la infancia, anticipan y revelan un carácter singular, una forma de predestinación-, pasando por el camino de pruebas que dan fe de su virtud, hasta el retorno al lugar desde donde habían empezado sus hazañas. Así pues, nos parece posible inscribir la dimensión biográfica de estos héroes-evocadores dentro de la "unidad nuclear del monomito" (Campbell 1959: 35) en la que el pasado se convierte en ciencia soteriológica, "fuerza mágico-religiosa más preciosa aún que la del que conoce el origen de las cosas" (Eliade 1999: 90). Conviene anticipar que dicha conformidad tampoco revela algo singular, sobre todo si consideramos que en las memorias encontramos "hechos y experiencias que [...] en gran medida son comparables y similares a lo largo del tiempo y el espacio" (Baena 2000: 487). Asimismo, y lo decimos con palabras de J. R. Echevarría (1961: 7), "el mito ha de expresar [...] lo que [...] vale para todos los tiempos [...] lo arquetípico, lo siempre presente, lo que no transcurre".

Para ilustrar el parentesco que puede hallarse entre los dos géneros, nos hemos servido de En la distancia (2004), de Josefina Aldecoa, y Sin rumbo cierto. Memorias conversadas con Fernando Valls (2000), de Juan Luis Panero. Estos escritores, nacidos respectivamente en 1926 y en 1942, comparten el hecho 
significativo de haber vivido sus infancias y adolescencias en el periodo de la Guerra Civil o en la época franquista. Esta coincidencia ha dejado secuelas en la personalidad de los que hemos considerado como héroes de un "reino de desmemoriados" (Morán 1991: 75), claramente consciente de que el individualismo burgués y la fe en el ser humano hacen del memorialista una alternativa al héroe convencional. Antes de adentrarnos en el análisis de las recurrencias temáticas en el corpus propuesto, se ofrecerá al lector una breve descripción de la acción que cada obra presenta, comenzando con el relato que, de los escogidos, se publicó primero, Sin rumbo cierto.

\section{LA LUCHA CONTRA LA MULTIPLICACIÓN DE PAdRES EN PANeRO}

En Sin rumbo cierto, nuestro héroe protagonista es Juan Luis y el antagonista es su padre, el poeta Leopoldo Panero. Las peripecias del personaje principal arrancan del influjo producido por la rigidez y la ortodoxia en los espacios cerrados y públicos. De entre los primeros recuerdos, el pequeño Panero lamenta una relación paterno-filial insatisfactoria que amplifica ese sentimiento de erradicación anunciado ya en el título de este proyecto memorístico. Así, en la casa de la infancia, la posible armonía entre los moradores se ve perturbada por el despotismo y la frialdad de un padre que, en un movimiento que va de lo exterior a lo interior, encarna los valores públicos imperantes. En efecto, el poeta Leopoldo, como director del Instituto de España en Londres bajo Franco, es un representante de la ley y, tal y como lo demuestra su Canto Personal, "un libro deplorable" (2000: 128), apoya al régimen. Esa inicial correlación empuja al niño a una primera rebelión y le deja entrever la existencia de otro orden posible que puede suplantar las deficiencias del adoctrinamiento político de su padre. A estas alturas, la casa de los abuelos maternos se configura no solo como un espacio de evasión del clima de alienación familiar, sino también como la cuna de una rudimentaria formación que desacraliza los insatisfactorios vínculos de filiación.

Dicha tensión entre el viejo y el nuevo orden de valores, encarnado respectivamente por el padre biológico y por el hijo, es puesta a prueba en los años de formación en el colegio, generando una ruptura definitiva con los ascendientes y con el revelado orden escolar. En el colegio al que es enviado, el Alfonso XII, Panero desarrolla una actitud de mal estudiante y numerosos son los actos de insubordinación contra los preceptores. Sin lugar a duda, dicho espacio se convierte en la prolongación del hogar doméstico con su malestar, puesto que en ambos se promueve una vigilancia continua y tiránica. Así, tanto el padre biológico como los padres del colegio, los agustinos, son invocados como símbolo del rechazo. Se critican no solo los métodos, sino también la educación impartida -"la enseñanza era ínfima, allí no se aprendía apenas nada. Seguían con Isabel y Fernando" (2000: 31)-, lo que impulsa la rebelión definitiva hacia el sistema escolar.

Antes de ser expulsado, el niño tiene un encuentro fortuito con un texto providencial, el de un poema del colombiano José Asunción Silva, que le revela su verdadero camino a seguir: la literatura. El libro posee una simbología exacta. 
Cirlot (1992: 277) señala su valor como "símbolo de poder para alejar a los espíritus malignos". En las manos del futuro escritor, el libro adquiere un valor reseñable y es primeramente fuente de revelación. Piénsese cómo las primeras lecturas proporcionadas por la abuela-mentora, así como las de las obras censuradas por el régimen, muestran al pequeño Panero la existencia de otro orden, otra realidad afín a su visión del mundo. De ahí el poder que este objeto emana para alejar la fuerza maligna del franquismo. Es más, en su conjunción con la pluma, como metonimia del proceso de escritura, el libro se convierte en símbolo de auctoritas -"el libro simboliza la ley" (Cirlot 1992: 76)- con que el escritor rescata y denuncia un pasado claustrofóbico.

Empuñando la pluma, el pequeño héroe entiende que puede servirse de la palabra para luchar contra las adversidades del tiempo que le ha tocado vivir, en un ajuste de cuentas con un pasado familiar y social poco solemne. La poesía se convierte así en reflejo de la vida, pero sobre todo en instrumento de ruptura. En torno a esta tensión se construye la identidad del personaje principal, que llega al presente de su oficio escritural como hombre nuevo, purgado de los valores del antiguo orden representados por esa multiplicación de padres. De ahí la reivindicación de un camino distinto, conquistado de cierta manera a través del autodidactismo. Ahora bien, el padre intenta a toda costa alejar al hijo de esa inclinación, obligándolo a estudiar Derecho. Juan Luis, al contrario, pasa todas las mañanas en la cafetería de la facultad de Filosofía y Letras, donde descubre sus simpatías hacia los grupos progresistas. Escribe así unos poemas sociales "tan parecidos a los de Neruda o a los de Blas de Otero" (2000: 54) que causan la ira del padre y provocan su expulsión definitiva del hogar doméstico. El regreso al lugar de origen, tras la búsqueda de una identidad literaria, coincide con la conversión de nuestro memorialista en "antifranquista consciente y [...] antileopoldopanerista" (2000: 50).

\section{Los AldecoA o del heroísmo en PAREjA}

En 2004, la leonesa Josefina Aldecoa publica su libro de memorias, En la distancia. El texto, que retrata un marco temporal que va desde el nacimiento de la escritora hasta el año 2003, se presenta como una narración fragmentaria de su entorno privado y social. Dentro de la obra es posible distinguir cuatro etapas de la vida personal fuertemente vinculadas con el tiempo histórico. La etapa de la niñez y la de la adolescencia, de más larga extensión y retratación, oscilan entre el recuerdo feliz de la República, la crueldad de la Guerra Civil y las prohibiciones del franquismo. La juventud convoca el clima de represión del régimen y la voluntad de evasión de un espacio tan opresor. La última etapa es la de la edad adulta donde la libertad propiciada por la democracia permite la recuperación de la memoria del pasado "para dejar testimonio a los que vienen después, de la verdadera, profunda, humana historia de España" (2004: 212).

Educada inicialmente a los principios republicanos y liberales, la infancia de Josefina Aldecoa se ve turbada por el final de la neonata República. A partir de ese momento, se perfilan dos tipos de educaciones: una educación tediosa y 
parcial impuesta por el Estado, y otra buscada y anhelada, "la gran literatura prohibida, los libros censurados y relegados al sótano" (2004: 37). Ahora bien, en En la distancia, al egotismo de la autorrepresentación se contrapone una heroicidad de pareja que, en todo momento, compensa la rigidez social del orden imperante. En efecto, en la obra, los héroes principales son el escritor Ignacio Aldecoa y su esposa, Josefina, que adoptará el apellido del marido tras enviudar en 1967. El régimen dictatorial, en la figura del caudillo y de todas las instituciones del poder oficial, antagoniza con el espíritu liberal del matrimonio.

La heroicidad de la pareja se revela, primeramente, en la quête, esa búsqueda que articula la aventura mesiánica de los dos sujetos. El viaje físico al extranjero revela así todas las disconformidades avaladas por el enemigo intestino, Franco. El contacto con lo foráneo se reduce precisamente a esto: a presentar un mundo aniquilado por la represión. Numerosos son los episodios donde Josefina e Ignacio, tanto en su patria como en el extranjero, presentan una lucha activa para el desbaratamiento del código de conducta impuesto. El héroe-transgresor que rompe con las leyes del orden imperante lo hace seguro de que lo ilegal de sus actancias encuentre una justificación en las deficiencias del sistema en el que vive. De alguna manera, es como si se denunciara la norma oficial a partir de las anti-normas de un mundo anhelado. Mediante estas actuaciones, se consolida el proceso de aprendizaje moral que debería dar paso a un nuevo orden.

En los recuerdos de nuestra memorialista, sí resulta claro que la acción heroica es el sacrificio que propiciará la victoria final. No obstante, la integración del sujeto en una deseada sociedad liberal pasa por las consecuencias de un doble óbito. Esta modalidad de cierre de la aventura culmina en la apoteosis personal de Josefina y la de su grupo de pertenencia, la llamada generación del medio siglo. De hecho, los efectos ruinosos de la muerte del marido quedan absorbidos por el renovado interés de Josefina hacia la creación literaria con la que cristalizar "esa historia que no se ve en los libros de texto de la Historia con mayúsculas" (2004: 212). Será la segunda muerte, la de Franco, que propiciará dicha recuperación, permitiendo a nuestra heroína empuñar la pluma y dar voz a un heroísmo que el silencio franquista y el olvido posdictatorial amenazaban con aniquilar.

\section{Automitografemas}

Ya prefiramos la lucha en solitario de Panero, ya nos atrape el heroísmo en pareja de los Aldecoa, lo cierto es que la lectura de sus obras nos muestra cómo la biografía de los dos memorialistas revela aspectos míticos, pues el recuerdo de la experiencia personal no solo se reviste de cierto heroísmo civil, sino que sobre todo es presentado en el texto a partir de situaciones constantes. Por esta razón en el apartado introductorio vinculábamos la narración de los elementos del monomito de Campbell con las unidades mínimas del recuerdo, los autobiografemas de Molloy, es decir "fragmentos de textos verdaderos a los que recurre el autobiógrafo para dar forma a lo que almacenó en la memoria" (1996: 16). Lo que nos ha llevado, llegados a este punto, a hablar de automitografemas, unidades 
mínimas de un recuerdo elevado a la categoría de mito, pues el memorialistanarrador crea un sujeto literario dotado de una virtud que lo distingue de los demás miembros de su comunidad. Las lecturas voraces y la proximidad a cierta ideología marxista en la infancia le han convertido en visionario de un mundo diferente, mejor. Por él emprende la aventura, tras haberse alejado o haber sido expulsado "desde el mundo de todos los días" (Campbell 1959: 35), sea la casa familiar o todo un país, lugar al que vuelve como hombre nuevo.

Adentrémonos ahora en el análisis de las recurrencias temáticas que se dan en el corpus propuesto. Con respecto a la primera etapa del monomito que da comienzo a la aventura del héroe, es decir la partida, aparecen en estos textos memorísticos muchos de los estadios que la caracterizan. En la primera jornada mitológica, el héroe es llamado a la aventura o por accidente o empujado por una fuerza exterior, "de alguna manera profundamente familiar al inconsciente" (Campbell 1959: 58), como podría ser la aparición de un guía, marcando el comienzo de un nuevo periodo. En las memorias que nos atienden sobresale la figura del mentor. Su papel es significativo en la infancia de nuestros héroes memorialistas, puesto que revela la existencia de un mundo mejor, libre del control fascista. Así, el pequeño Panero es adoctrinado por su abuela -"nos reíamos como locos con los discursos de Franco por la radio" (Panero 2000: 37)- que, desafiando el orden imperante, en el espacio de la casa familiar, profesa su credo democrático. En Aldecoa, protagonista de la breve experiencia republicana, el mentor parece operar in absentia. La muerte de su maestro, fusilado porque acusado de "tratar de politizar a los alumnos" (Aldecoa 2004: 26) una vez asentado el franquismo, marca el comienzo de una etapa de la concienciación acerca de las aniquilantes instancias totalitarias. El mentor, que subrepticiamente o menos inocula el virulento cultivo democrático, propicia la llegada de una fiebre lectora que ha de formar al futuro héroe. Tanto Panero como Aldecoa atestiguan lecturas precoces e indomables, tópico de la autorrepresentación este que les sirve "para poner de manifiesto la precocidad y el carácter" (Caballé 1975: 115). ¿Acaso no nos encontramos frente a una primera señal de la futura grandeza? Es más, dicha ocupación formativa podría constituir la razón de la inicial abulia al llamado, lo que "convierte la aventura en una negativa" (Campbell 1959: 61). Habrá que esperar el final de la epidemia lectora para que el héroe se entregue por completo a su destino y cruce el umbral. De hecho, y lo decimos con palabras de Meletinski (2001: 286), "la formación tiene un carácter negativo y termina con el héroe casi por completo ajeno al ambiente [...] que lo rodea". De ahí la necesidad de salir hacia lo desconocido.

Queda inaugurada así la segunda etapa de la historia del héroe, la de la iniciación, "en donde debe pasar por una serie de pruebas" (Campbell 1959: 95). Como consecuencia del tono fuertemente realista de los textos que analizamos, no aparecen amuletos mágicos ni ayudantes sobrenaturales. De hecho, nuestros dos héroes se enfrentan al enemigo común, el tiempo histórico encarnado por Franco, con las únicas armas de la creatividad y del anhelo democrático que les fue instilado. Las pruebas que demostrarán una trayectoria vivencial singular con respecto al resto, esa grandeza que ha de convertirles en ejemplos a imi- 
tar, se dan ya en los comienzos de la adolescencia. El marco de actuación es el colegio y, en concreto, las escuelas del régimen, instituciones a las que los dos memorialistas se rebelan, puesto que estas apoyan y difunden el ideario franquista. Con respecto a Juan Luis Panero, especulando un tanto en los detalles de las escenas-recuerdo que el narrador cristaliza en sus memorias acerca de este periodo, es posible leer en su buscada expulsión del colegio ese rechazo ulterior del padre en la figura de los agustinos, los padres del colegio, lo que, en última instancia, convoca un democrático deseo parricida del pater patriae, Franco. En septiembre de 1955, según precisa indicación del narrador, el pequeño Panero es enviado al Escorial. Este espacio llega a representar la prolongación del hogar doméstico y su malestar. La secuencia de adjetivos que Panero encadena para la descripción del sitio revela su sufrimiento por el clima de represión. De hecho, el colegio es presentado como una "tumba oscura" (2000: 29) de "heladas galerías" (2000: 30), donde unos curas amanerados, "de voz meliflua" (2000: 30) y "con su repugnante olor a sacristía" (2000: 29), ejercían su autoridad. Significativo es el recuerdo de uno de los castigos infligidos, que casi recalca el sufrimiento de Jesús para expiar los pecados de la humanidad: "nos tuvieron [...] con los brazos en cruz, hasta las tres de la madrugada" (2000: 30). Se critica también la utilidad de la educación impartida, catalizador de la rebelión hacia el sistema escolar. Tómense, como ejemplos concretos, el deniego del pequeño Panero a leer los poemas de su padre en las fiestas escolares o a revelar su verdadera profesión para no ser señalado como el "hijo del poeta franquista" (2000: 95). Asimismo, el narrador rememora con espíritu irreverente sus actos de insubordinación y el deleite de la primera masturbación, episodio erótico que, siguiendo a Gonzalo Navajas (1987: 25), leemos como un acto de clara rebelión a un sistema de tipo totalitario.

Anodinas son también las clases de Josefina Aldecoa. Exceptuando la apología del programa escolar republicano, en su escrito memorístico no se recoge ningún recuerdo de valor positivo asociado con la experiencia formativa en los años del franquismo. De hecho, la deficiencia y la rigidez de la educación impuesta se repite en las etapas del bachillerato y de la universidad: "los libros que tuvieran un mínimo contenido alarmante habían desaparecido" (2004: 34); "estábamos escasos de estímulos literarios y artísticos" (2004: 38); "la censura gravitaba sobre todas las asignaturas y la biblioteca se veía limitada y disminuida por la misma razón" (2004: 43); "la facultad, desde el punto de vista académico, era aburrida" (2004: 44). Se perfilan, de esta manera, dos tipos de educaciones. La primera, tediosa y parcial, que es la del Estado. La segunda, anhelada, que une autodidactismo e impavidez ante los controles censores del régimen. Es así como Josefina emprende un heroico camino de búsqueda que la llevará al descubrimiento de lugares clandestinos donde no solo entra en contacto con la literatura censurada, sino también con toda una generación de desafiliados del régimen. Esta cuestión, la de la presencia de una comunidad antifranquista, es central para Aldecoa, ya que postula una formación sigilosa que reemplaza el oscurantismo ideológico del Estado. Las reuniones secretas en subrepticias ins- 
tituciones de izquierda, las tertulias en cafés y tabernas ${ }^{1}$, el intercambio de libros censurados guía y alimenta la lucha de nuestra heroína que, tras haber cruzado el umbral doméstico, asiste a las primeras victorias preliminares.

Esta fase de la iniciación, con sus pruebas y obstáculos, llega a su culminación cuando nuestros héroes memorialistas viajan al extranjero. La llegada a los países democráticos sirve como motivo de confrontación entre el espacio español, asfixiante y alienante, y el foráneo. En términos generales, es posible afirmar que todo lo exótico se configura como marco de evasión y de enriquecimiento cultural, puesto que el relato del viaje aparece salpicado por las continuas referencias a lecturas de obras o visiones de películas prohibidas en la España de Franco. Particularmente se pone énfasis en la rememoración de las sensaciones que acompañan dichos descubrimientos y que impulsan, como tendremos manera de apreciar, las últimas aventuras. En Sin rumbo cierto, por ejemplo, Juan Luis Panero recuerda las innumerables lecturas de los libros proscritos y perseguidos por la censura, pero también el encuentro con los exiliados y los paseos despreocupados por las calles de las ciudades visitadas. Los varios regresos a España le ven protagonista de diferentes luchas contra los guardianes del umbral, los aduaneros, en su tentativa de introducir en el territorio peninsular obras prohibidas como la de Lenin o de Jean Genet, entre otras. Asimismo, Josefina Aldecoa rememora la emoción frente a la bandera del partido comunista ondeando en un edificio parisino, los títulos tentadores que las librerías exponían públicamente, los besos de una pareja bajo una farola junto al Sena, pero sobre todo los engaños urdidos por nuestra heroína y su marido para viajar a los países que figuraban como prohibidos: "Dionisio Ridruejo nos consiguió un visado especial que se eliminaba al regresar sin dejar huellas en el pasaporte" (2004: 128).

Tercera y última etapa en la historia del sujeto heroico es la del regreso. Este, por haber conocido un orden distinto al de su mundo ordinario, detiene ahora los misterios de la sabiduría y ha de traerlos a su tierra. Tras el cruce del umbral del regreso, el héroe se encuentra en la necesidad de aceptar "las banalidades y las ruidosas obscenidades" (Campbell 1959: 201) de su comunidad de pertenencia. Así, cuando en octubre de 1970 regresa de los Estados Unidos y de México, Panero (2000: 135) declara que Madrid le "fatigaba mucho [...] y especialmente aquella larga agonía del franquismo que no se acababa nunca". Con mucha mayor precisión, Aldecoa recuerda su asombro frente a la visión de Nueva York en 1958 - "Ilegar a Nueva York a primeros de octubre fue extraordinario" (Aldecoa 2004: 105)-. Pero, tras volver de ese "reino de los dioses" (Campbell 1959: 200) a "aquel Madrid [...] en el que la censura funcionaba en la prensa, la radio y la [...] televisión" (Aldecoa 2004: 123), también nuestra heroína lamenta la falta de libertad de la que ella y su comunidad de pertenencia son víctimas. Sin

\footnotetext{
${ }^{1}$ Así lo recuerda Josefina Aldecoa (2004: 82): "Situaciones históricas como la de nuestra posguerra favorecen las reuniones en lugares, abiertos a todos a la vez que neutros, que adquieren un carácter de refugio y propician la creación de grupos de amigos con intereses comunes que necesitan verse y encontrarse constantemente. Ese es el caso de los cafés -'catacumbas" los llamaba Buero Vallejo-. Todo ello tiene relación con la atmósfera claustrofóbica del país y la ciudad en la que se está viviendo".
} 
embargo, el sujeto elegido, en virtud de esa fuerza mágica, sobrenatural, que le ha transformado, sobrevive al impacto. Es un hombre nuevo y puede actuar sin ningún miedo, sumándose a la lucha contra el enemigo común, animándola. Panero ya no teme la ira de su padre. Escribe poemas sociales y participa en unos actos de agitación -"cantamos la Internacional [...] en el paraninfo de una universidad franquista" (Panero 2000: 53)- que, según atestigua en sus memorias, llevarán a la caída del ministro de Información y Turismo, Arias Salgado, y al ascenso de Fraga con quien "empezó una tímida apertura" (Panero 2000: 53). Los Aldecoa, Josefina e Ignacio, tampoco dudan en participar activamente. Ignacio tomará parte en lo que el régimen calificará como contubernio de Múnich, un encuentro con la España del exilio en ocasión del IV Congreso del Movimiento Europeo en 1962. Josefina, por su parte, rememora las doce horas encerrada en el Ministerio de la Gobernación por su participación en una manifestación, en Puerta del Sol, de mujeres madrileñas que se solidarizaban con las mujeres de los mineros asturianos torturados. El triunfo se coronará con la muerte de Franco y la victoria final de las fuerzas positivas, las democráticas, de las que el héroe es portador.

\section{CONSIDERACIONES FINALES}

Al llegar a este punto, el lector paciente e interesado se habrá dado cuenta de que muchas veces hemos esparcido en nuestro estudio expresiones que inciden en el heroísmo de los protagonistas de las obras analizadas. Panero y Aldecoa, autores-narradores-personajes principales del relato, experimentan un rechazo con respecto al ambiente que los rodea. Debido a una subrepticia educación marxista impartida en tiempos totalitarios, experimentan ya en la infancia ciertas vivencias que han de encaminarlos hacia lo extraordinario en una lucha arquetípica entre Bien y Mal, experiencia de la que quieren dejar constancia en sus textos. En nombre de la autorreferencialidad, apelan a la Historia como suceso vivido, logrando, a través de la escritura, desprivatizar lo personal e insertarlo dentro de una estructura que ordena y espectaculariza el recuerdo. En su conjunción con la Historia, como ya sugiere Mardones (2000: 57), la vida "se sitúa en estrecha relación con el mito, ya que este está en la raíz de la comprensión del sentido de la realidad". Y, en efecto, lo que estas obras sacan a relucir es la identidad de un sujeto que se construye en relación con un mundo exterior que intenta descifrar y que es también la proyección de las aspiraciones de su comunidad, "de las presiones más imperativas y perturbadoras de la existencia social" (Caillois 1988: 13). En la persona del memorialista-testigo parece entonces resumirse la voluntad de "alcuni gruppi di cittadini o certe categorie sociali [...] di iscrivere indelebilmente nel divenire storico il loro intervento specifico" (Burstin 1986: 85).

Como hemos tenido manera de apreciar, los recuerdos de Juan Luis Panero y de Josefina Aldecoa, si aislados en unidades temáticas constitutivas de la narración, se dejan encasillar en las tres etapas que forman el monomito de Campbell y en las que se articula la aventura del héroe. Desde esta perspecti- 
va resulta tentador plantear la creación contemporánea de mitos. Ahora bien, ¿cómo entender la integración de esta estructura? Hay que apuntar, primeramente, la coincidencia morfológica entre relato memorístico y relato del héroe. De hecho, sobre ambos grava el apremio de reducir el material literario en elementos constantes de una narración que, para cautivar al lector, ha de elaborar experiencias simbólicas comunes a todos los hombres (May 1992: 26-30; Vigna 2019: 39-40). Pero, más fundamentalmente, debemos comprender dicha integración como manifestación de una voluntad narrativa que propone modelos con los que dar sentido y orientación a la realidad.

Cada memorialista, al contar su propia vida, al empuñar la pluma y sirviéndose de la auctoritas de su oficio, ha elevado su vida a exemplum, modelo no solo para los que fueron testigos directos de esos años de oscurantismo, sino también para los lectores de todos los tiempos. Estos, apelándose a la referencialidad que procede del nombre propio, consagran unos héroes de carne y hueso, héroes vivos, hijos de un reino de la desmemoria. En el marco del siglo $\mathrm{XXI}$, este tipo de producción literaria se puede relacionar con la necesidad todavía apremiante de dar voz a lo silenciado, de dar a conocer otra versión más de lo acaecido, en una férrea oposición a la circulación de la única versión de la Historia "fabricada arteramente por los vencedores" (Torres 2002: 14) durante los cuarenta años que duró el régimen. De esta manera, logran salvar del olvido destructor retazos de experiencias vividas que el olvido posdictatorial amenazaba con aniquilar.

\section{OBRAS CITADAS}

Aldecoa, Josefina (2004). En la distancia. Madrid: Alfaguara.

Baena, Rosalía (2000). "Childhoods: la autobiografía de infancia como subgénero narrativo en auge". Rilce. Revista de Filología Hispánica, 16.3: 479-489. <https://dadun.unav. edu/bitstream/10171/5351/1/Baena\%2c\%20Rosal\%c3\%ada.pdf> (16 de septiembre de 2019).

Becerra Mayor, David (2015). La Guerra Civil como moda literaria. Madrid: Clave Intelectual. Burstin, Haim (1986). "Protagonisti, protagonismo e evento rivoluzionario", Cheiron, 6: 85104.

Caballé, Anna (1975). "Figuras de la autobiografía", Revista de Occidente, 74-75: 103-119.

Caillois, Roger (1988). El mito y el hombre. México: Fondo de Cultura Económica.

Campbell, Joseph (1959). El héroe de las mil caras: psicoanálisis del mito. México: Fondo de Cultura Económica.

Cirlot, Juan-Eduardo (1992). Diccionario de símbolos. $9^{a}$ edición. Barcelona: Labor.

Duch, Lluís (1998). Mito, interpretación y cultura. Aproximación a la logomítica. Barcelona: Herder.

Echevarría, José Rafael (1961). "Eritis sicut dii", Asomante, 17.3: 7-36.

Eliade, Mircea (1999). Mito y realidad. Barcelona: Kairós.

Fernández Prieto, Celia (1997). "Figuraciones de la memoria en la autobiografía", in Claves de la memoria, ed. Amalio Blanco y José María Ruiz-Vargas. Madrid: Trotta, 67-82. 
Mardones, José M. ${ }^{a}$ (2000). El retorno del mito. La racionalidad mito-simbólica. Madrid: Síntesis.

May, Rollo (1992). La necesidad del mito. La influencia de los modelos culturales en el mundo contemporáneo. Barcelona: Paidós.

Meletinski, Eleazar M. (2001). El mito: literatura y folklore. Tres Cantos (Madrid): Akal.

Molloy, Sylvia (1984). "At Face Value: autobiographical Writing in Hispanoamerica", Dispositio, 9.24/26: 1-18.

Molloy, Sylvia (1996). Acto de presencia. La escritura autobiográfica en Hispanoamérica. México: Fondo de cultura económica.

Morán, Gregorio (1991). El precio de la transición. Madrid: Akal.

Navajas, Gonzalo (1987). Teoría y práctica de la novela española posmoderna. Barcelona: Edicions del Mall.

Panero, Juan Luis (2000). Sin rumbo cierto. Memorias conversadas con Fernando Valls. Barcelona: Tusquets Editores.

Pozuelo Yvancos, José María (2004). "Autobiografía: del tropo al acto del lenguaje", in Autobiografía en España: un balance. Actas del Congreso Internacional celebrado en la Facultad de Filosofía y Letras de Córdoba del 25 al 27 de octubre de 2001, ed. Celia Fernández Prieto y María Ángeles Hermosilla Álvarez. Madrid, Visor, 173-181.

Savater, Fernando (1986). La tarea del héroe (elementos trágicos para una ética trágica). Madrid: Taurus.

Torres, Rafael (2002). Víctimas de la guerra. Madrid: Oberon.

Vigna, Gaetano Antonio (2019). Aproximación crítica a la escritura memorística publicada en España entre los años 2000 y 2018. Tesis doctoral inédita. Universidad de VaIladolid. 